\title{
Banalidade do mal em comentários de leitores: internet e disseminação da intolerância ${ }^{1}$
}

\section{Carlos Alberto Carvalho}

\section{Resumo}

A partir de comentários de leitores sobre narrativas jornalísticas acerca de acontecimentos envolvendo crimes de proximidade contra mulheres em relações de gênero, 0 artigo, de natureza ensaística, busca no conceito de banalidade do mal compreender dinâmicas de intolerância. Ao mesmo tempo em que assumimos clara militância contra as formas de preconceito, ódio e demais modalidades de depreciação humana, alertamos para a necessidade de pensar os próprios pressupostos teóricos que podem conduzir pesquisas na área da Comunicação a não prestarem atenção às contradições sociais, aos jogos de poder e à recusa à aceitação da diferença como princípio constitutivo da riqueza humanossocial.

\section{Palavras-Chave}

Banalidade do mal. Comentários de leitores. Intolerância

Carlos Alberto Carvalho I carloscarvalho0209@gmail.com Doutor em Comunicação Social pela Universidade Federal de Minas Gerais. Professor do Departamento de Comunicação Social da UFMG, na graduação e no Programa de Pós-Graduação em Comunicação. É um dos coordenadores do Grupo de Estudos Tramas Comunicacionais: Narrativa e Experiência.

\section{Introdução}

Assumindo, de imediato, a natureza ensaística deste escrito, a partir de uma base empírica constituída por comentários de leitores na internet sobre narrativas jornalísticas que tratam de violências de gênero contra mulheres em crimes de proximidade, queremos esclarecer ainda que nos anima 0 espírito de militância contra 0 mal e a intolerância que se espraiam pela rede, mas não somente nela. Tentamos compreender, nos marcos da filosofia política de Hannah Arendt, como a banalidade do mal está talvez mais evidente entre nós do que nunca esteve, exceção, naturalmente, ao período do totalitarismo nazista que marcou a vida da filósofa, levando-a a pensar não somente no mal que, banalmente, se instala e se espraia, mas ainda a indicar que se viviam, então, tempos sombrios. Pois tempos sombrios no que se refere ao mal e à intolerância também vivemos, e reconhecê-los não é exercício niilista ou afogar-se na desesperança imobilizadora. É, ao contrário, compreendê-los em suas formas de manifestação como estratégia para combatê-los com vigor. Mais especificamente para os nossos propósitos, 
compreender como as relações de gênero são o pano de fundo a partir do qual o mal e a intolerância se banalizam no corpus constituído por comentários de leitores que investigamos.

A recusa ao diferente na sociedade brasileira, ou em outros termos, à alteridade, tem se mostrado com faces diversas, atingindo não somente níveis individuais e coletivos, mas também institucionais. Não por acaso, trocas de mensagens na lista de e-mails da Associação Nacional dos Programas de Pós-Graduação em Comunicação (Compós) em tempos recentes chamaram a atenção para 0 inusitado de um espaço supostamente favorável às visões que reconhecem as diferenças e se pauta por posturas resultantes de compreensões fundadas em princípios teóricos e rigor metodológico ter sido palco para demonstrações do mal e da intolerância. Referimo-nos à repercussão da notícia, seguida de abaixo-assinado tentando reverter a decisão, de suspensão da Cátedra Michel Foucault pelas autoridades religiosas, contra decisão acadêmica da PUC de São Paulo, por elas mantida, que teve entre os intervenientes um religioso a defender 0 acerto da decisão, dado 0 caráter pernicioso e pecaminoso do pensamento e do personagem Foucault. No nível individual, a notícia certamente desconcertante de um professor vítima de racismo por parte de uma aluna, em sala de aula de curso de comunicação, é outro indicativo do alcance da intolerância, do preconceito e da negação da alteridade. Parafraseando um jargão dos estudos gays apropriado pela mídia ao referirse ao arrefecimento das reações homofóbicas imediatamente após decisão do Supremo Tribunal Federal (STF) de estender a homossexuais alguns direitos que lhes eram negados, "os intolerantes saíram do armário". Em sentido tristemente mais amplo, intolerantes e adeptos do mal, de forma generalizada, saíram do armário, ainda que, no caso dos comentários de internet, na maioria das vezes protegidos pelo anonimato, outra faceta do modo como operam no submundo e nas trevas quem é incapaz do convívio politicamente heterogêneo e negociado.

Exemplos da intolerância se multiplicam, muitos deles aplaudidos/incentivados por programas midiáticos jornalísticos e de entretenimento, por meio de seus repórteres e apresentadores, além de pregadores religiosos que claramente incitam, pelo rádio, pela internet e pela televisão, intolerâncias diversas, supostamente em nome da bíblia e para cumprir mandamentos divinos. Noticiários estão repletos de casos de linchamentos por suspeitas de crimes (e, ressalte-se, são injustificáveis em quaisquer circunstâncias), apedrejamento ou espancamento à morte por intolerância religiosa, sem contar os diversos episódios de homofobia, misoginia, racismo, xenofobia e outras modalidades de violências físicas e simbólicas. No plano das lutas político-partidárias, ministros de Estado e ex-ministros são agredidos em 
restaurantes e hospitais, enterros de políticos desafetos são acompanhados por cartazes festejando aquela morte e desejando outras, sem contar cartazes em manifestações de rua pedindo a volta da ditadura militar, lamentando que a presidenta brasileira não tenha sido morta quando das torturas a que foi submetida e outras formas de retrocesso da vida democrática.

Se não constituímos caso isolado de sociedade na qual tais manifestações, em totalidade ou em partes, também se verificam, somos uma das que mais praticam tais atos. Antes de constituir uma explicação, para alguns justificativa, esse quadro indica tratar-se de problema político-cultural global, o qual exige ações efetivas de pessoas, governos e organismos supranacionais. Mas também 0 engajamento das mais diversas áreas acadêmicas e intelectuais na compreensão desses fenômenos, em esforço conjunto de superação.

\section{A tolerância, é importante deixar claro de} antemão, não a entendemos como a máscara cínica que mal disfarça o ódio, a indiferença, os rancores e todas as manifestações de preconceito, como a sociedade brasileira tão bem parecia cultivar, mas episódios recentes fizeram cair por terra. Ou talvez tenham chamado a atenção para uma característica atávica da nossa sociedade, cultivadora do cinismo e do faz de conta, hábil em varrer para debaixo do tapete nossas dificuldades de convívio plural, em todas as dimensões culturais, religiosas, comportamentais e políticas, com as exceções de praxe, pois, afinal, não vivemos uma realidade de absoluta barbárie e é necessário evitar que tal aconteça. Pensamos a tolerância, em consonância com o humanismo radical de Paul Ricoeur, como o absoluto reconhecimento da alteridade, sem adversativos da espécie de "mas", "apesar de". Alteridade que tem no princípio de reconhecer-se como um outro o ponto máximo de ação (RICOEUR, 1991), pois aciona minha capacidade de colocar-me no lugar do outro a partir da minha própria condição de quem se transforma ao longo dos anos. Nos termos do autor, a dialética entre ipseidade e mesmidade. Em sentido prático e em livre adaptação, enxergarme velho quando ainda jovem é reconhecer minha alteridade futura que deve, eticamente, me levar a considerar os velhos com os quais convivo na atualidade, e vice-versa, quando velho convivo com os jovens que um dia fui. Se aplico esse princípio relativamente a todas as pessoas que são diferentes de mim, a tolerância pela via do reconhecimento pleno da alteridade se transforma de utopia em realidade.

0 exercício da tolerância atrela-se, desse modo, a atitudes éticas que não podem prescindir de processos de transformações morais e culturais a partir, precisamente, do reconhecimento da riqueza e da beleza das diferenças e da diversidade, portanto, não da sua negação. Por ser um projeto utópico, o cultivo da ética da tolerância, requisito fundamental para combater o mal, requer militância em todas as esferas e, entendemos, a intelectual é uma das mais privilegiadas e essenciais, exatamente por seu 
poder de disseminação e, até prova em contrário, de construir métodos e teorias capazes de lançar luzes sobre suas dinâmicas e, a partir daí, possibilitar estratégias de superação.

Antes de avançarmos, uma breve descrição da empiria que chamou nossa atenção para a banalidade do mal em comentários de leitores na internet. Na realização de pesquisa de pósdoutoramento intitulada Jornalismo e crimes de proximidade contra mulheres: análise de notícias publicadas em sites do Brasil e de Portugal $^{2}$, ficou evidente a agressividade de comentários, da parte de leitores brasileiros em especial, contra mulheres vítimas de violência em crimes de proximidade em relações de gênero, assim como também dirigida aos algozes. A coleta foi realizada nos sites $U O L$, brasileiro, e do jornal Público, português, pelo período de dois meses, entre fevereiro e abril de 2015, recolhendo narrativas jornalísticas e comentários de leitores. Não é um corpus que tenha pretensões de representatividade estatística ou que constitua série histórica, dentre outras razões, por tratarse de proposta de investigação que prevê outros desdobramentos a partir dos resultados teóricos e metodológicos obtidos. Embora a perspectiva de análise da banalidade do mal não estivesse contida no plano de trabalho inicial, ela se impôs pelo choque que os comentários de leitores nos causaram. Ao recorrermos aos comentários, não pretendemos análises comparativas sobre o comportamento de leitores brasileiros e portugueses, concentrando-nos nas atitudes dos leitores do Brasil. Como curiosidade, 0 comportamento dos leitores portugueses no mesmo corpus é bastante distinto, ainda que com algum traço da banalidade do mal, segundo as premissas que adiante discutiremos sobre este conceito e suas potencialidades para esclarecimento das reflexões aqui desenvolvidas.

Metodologicamente, as narrativas jornalísticas e os comentários que as acompanharam foram lançados em um banco de dados digital, o que nos permitiu totalizar os comentários e sua média relativamente ao número de narrativas recolhidas, configurando a dimensão quantitativa da pesquisa. Qualitativamente, observamos as fotos ou ilustrações que acompanharam os comentários, bem como os nicknames, considerando-os, conforme os pressupostos narrativos de Paul Ricoeur (1994), como parte da tessitura da intriga, pois nos informariam sobre sentidos ligados à banalização da violência e do mal, segundo a lógica da tríplice mimese. A tríplice mimese, em síntese, diz da configuração mediadora da textuação (mimese 2) relativamente ao mundo prefigurado (mimese 1), no qual estão pressupostos éticos, morais, culturais, políticos etc., os quais, uma vez integrados à narrativa, serão reconfigurados pela leitura como ação sobre 0 texto (mimese 3). Trata-se, portanto, da articulação temporal passado-presente-futuro, 
dimensão heterogênea que se soma à discordância entre acontecimentos distintos que culminarão no que Paul Ricoeur denomina de "síntese do heterogêneo" ou "discordância concordante". Além de encerrar em si um circuito hermenêutico virtuoso, à medida que as narrativas estão em permanente fluxo de construção, leitura/ interpretação e novas construções, a tríplice mimese representa fluxos comunicacionais que se realizam pela capacidade de as narrativas nos colocarem em diálogo com textos, sociedades e culturas. Esse circuito comunicativo, também ele virtuoso, nos permite conhecer as narrativas de uma determinada sociedade, assim como nos reconhecermos a partir do que tais narrativas nos ofertam como mundos do reino do "como se", para outra vez utilizar expressão de Paul Ricoeur, bem como mundos configurados de acordo com as lógicas do real feitas circular, por exemplo, pelo jornalismo.

Menos do que uma teorização sobre a internet e a própria dinâmica dos comentários de leitores que nela são divulgados, interessam-nos como temática a banalidade do mal e a intolerância que nesses comentários são manifestos. Por outro lado, teceremos algumas considerações acerca de limites teóricos e metodológicos em estudos comunicacionais que têm contribuído, em determinadas situações, para análises nas quais as contradições sociais são postas de lado, como se processualidades e produtos da comunicação se apartassem das dinâmicas socioculturais, com suas clivagens e problemas de variadas ordens.

\section{Sobre a banalidade do mal e a intolerância}

Se a publicação das reportagens originalmente produzidas para The New Yorker, posteriormente transformadas em livro, do Eichmann em Jerusalém: uma reportagem sobre a banalidade do mal (2014), foi cercada de polêmicas e acusações de teor político, especialmente vindas de comunidades judaicas, de que Hannah Arendt teria sido simpática ao carrasco nazista, a autora enfrentou também críticas sobre 0 alcance da noção de banalidade do mal para a correta explicação do que leva homens como Adolf Eichmann a agirem irrefletidamente em nome da obediência aos comandos superiores. Ainda que a ideia de banalidade do mal tenha aparecido como a novidade da filosofia política de Arendt no Eichmann, muito do que gerou desconforto já havia sido objeto de reflexões em seu livro anterior, As origens do totalitarismo (1989). Por exemplo, sem que isso implicasse julgamento ético ou moral, o fato de os próprios judeus terem sido parte da engrenagem que os levou ao extermínio nos campos de concentração, por meio dos Conselhos Judaicos, aos quais o nazismo impôs recenseamentos e indicações daqueles que deveriam ser conduzidos aos locais de matança e trabalhos forçados, ou ainda pela crença de que 0 antissemitismo europeu era dirigido prioritariamente contra judeus pobres, o que livraria os demais de perseguições.

Os detalhes sobre as polêmicas podem ser esmiuçados a partir da bibliografia que aqui 
utilizamos, ela própria remetendo a outras indicações, uma vez que detalhá-las foge ao escopo desse escrito. No entanto, delineá-las minimamente nos permitirá compreender que, ao contrário de uma atitude de desconsideração pelo sofrimento do povo judeu - seu próprio povo -, Hannah Arendt quis, ao apontar para a corresponsabilização, alertar para a necessidade de percepção dos movimentos que criam as condições para a instauração do terror e do extermínio a partir da intolerância e do mal. Nesse sentido, quando cotejamos com outros episódios anteriores ao antissemitismo nazista, por exemplo, o descrito por Jean-Dennis Bredin (1995) relativamente ao Caso Dreyfus, na França, evidencia-se que havia um rastilho de ódio pelo povo judeu disseminando-se pela Europa, o que poderia, se adequadamente percebido, ao menos ter mitigado os efeitos do holocausto patrocinado por Hitler. Na outra ponta da polêmica, Arendt teria mesmo reduzido o alcance do impacto do mal ao pensá-lo em termos de banalidade e não de mal radical, como afirmam alguns críticos? Nos dois extremos, há elementos fundamentais para pensarmos o mal e a intolerância na sociedade brasileira contemporânea, manifestos nos comentários de leitores sobre notícias da internet relativas a crimes de proximidade contra mulheres em relações de gênero.

Ainda nos marcos do problema da corresponsabilização, é importante perceber que as argutas observações de Arendt sobre 0 papel desempenhado pelos Conselhos Judaicos e pela não identificação do alcance do antissemitismo servem como chave histórica para a necessidade de identificar, ainda no nascedouro, projetos políticos autoritários e totalitários. Contudo, especialmente para que não se tenha a ilusão de que projetos políticos totalitários nasceriam de espécies de laboratórios estatais ou políticopartidários, mas tendem, ao contrário, a chegar a esses locais quando já fazem parte de sentimentos coletivos relativamente difusos. Em termos mais precisos, identificar o ódio, o preconceito e a intolerância e suas dinâmicas na sociedade brasileira atual é tarefa urgente, para a qual estudos no campo da comunicação têm muito a oferecer, com o cuidado de evitar análises maniqueístas e de unilateralidade.

Ainda a propósito do período que antecedeu 0 holocausto promovido pelos nazistas, estudos sobre homossexualidade (SPENCER, 1996; NAPHY, 2004; ERIBON, 2008; SCHWAB \& BRAZDA, 2011) indicam que a Alemanha pré-Hitler era quase um "paraíso" para homossexuais, os quais também foram conduzidos aos campos de concentração, ao lado dos judeus, ciganos, Testemunhas de Jeová, comunistas e demais inimigos eleitos pelo projeto de poder nazista. Diversos, portanto, foram os grupos sociais que não perceberam a tempo o clima político que se avizinhava, deixando de articular estratégias políticas para combatê-lo. No entanto, distintas também têm sido as ênfases sobre aqueles que sofreram as agruras dos campos de concentração e extermínio, como demonstra a pequena bibliografia, em área que temos 
investigado, a partir do problema da homofobia, do holocausto imposto aos homossexuais. No próprio Eichmann, Arendt dedica apenas uma citação a essas vítimas do nazismo e não parece ser ao acaso, pelo contrário, indica as dificuldades históricas de reconhecimento e enfrentamento de preconceitos mais arraigados e mais disseminados em praticamente todas as sociedades do passado e do presente.

Mas voltemos ao foco das críticas políticas de que Arendt foi alvo, para compreendermos que, efetivamente, a autora nota uma peculiaridade fundamental no nascedouro e crescimento dos totalitarismos, qual seja, a de que eles não seriam possíveis caso a resistência a eles se fizesse vigorosa desde 0 início. E por que não foi assim, ao menos no surgimento dos totalitarismos europeus dos períodos das guerras mundiais e da política de extermínio implantada na União Soviética comunista? Embora Arendt não se tenha ocupado de todas essas formas de totalitarismo igualmente, nota-se que a um estágio de desejo social difuso, transformado em programa de governo e daí em projeto de Estado, o uso da força passa a ser ingrediente fundamental para a sobrevida de tais regimes políticos. Nem por isso os poderes totalitários são eternos, como demonstra a queda de ditaduras ao redor do mundo, a partir da ação política que as combate em nome da democracia ou projetos de outra natureza, por exemplo, econômicos, que não necessariamente levam a regimes efetivamente igualitários ou respeitadores de todos os princípios de defesa e garantia dos direitos humanos.

E a banalidade do mal, em que consistiria mais precisamente? Em correspondência posterior à publicação do Eichmann mantida com Gershon Scholem, que manifestara não estar convencido do acerto da tese da banalidade do mal, Hannah Arendt defende que o mal nem sempre é radical.

Tenho hoje, com efeito, a opinião de que o mal nunca é "radical", que ele é apenas extremo e de que não possui nem profundidade, nem qualquer dimensão demoníaca. Ele pode invadir tudo e assolar o mundo inteiro precisamente porque se espalha como um fungo. Ele "desafia o pensamento", como disse, porque o pensamento tenta alcançar a profundidade, ir à raiz das coisas, e no momento em que se ocupa do mal sai frustrado porque nada encontra. Nisso consiste a sua "banalidade". (ARENDT, 2014, p. 25 , com destaques no original)

As críticas sobre os eventuais limites conceituais da banalidade do mal, como se percebe, são mais complexas do que aquelas dirigidas às dimensões políticas da percepção do personagem Adolf

Eichmann por parte de Hannah Arendt, ainda que não estejam desatreladas. Trata-se de um embate que tende a situar a compreensão da banalidade do mal à ideia de mal radical em termos da escolha filosófica entre a ação ética e a ação política. Nas palavras de António Marques,

Porém, numa direcção muito diferente daquela que é proposta por Arendt, é possivel uma compreensão do mal como conceito-chave da vida ética, repondo assim o próprio conceito de vida ética com autonomia face à esfera do político. (MARQUES, 2015, p. 110, com destaques no original) 
Para 0 autor, Arendt, que fundamenta muito da sua argumentação sobre 0 mal a partir de Kant, 0 abandona quando desacredita na existência do mal radical, resultante do desvirtuamento do agir ético, para pensar o mal em termos da ação política. A complexidade filosófica das relações entre ética e política, nos termos da oposição indicada por António Marques, foge às nossas competências e objetivos, mas é importante assinalar que é a necessidade de colocar em cena a política, o que leva Arendt a situar 0 agir ético nessa esfera como essencial para 0 entendimento de como pessoas comuns, sem as características dos monstros arquetípicos, são capazes de praticar o mal sem sobre ele refletir. Em certo sentido, ela percebe o limite da liberdade necessária à superação do mal radical diante de situações extremas, fazendose urgente compreender quais mecanismos a política faz atuar sobre a consciência ética, a partir do Eichmann com o qual ela depara durante 0 julgamento.

Recorrendo a Nádia Souki,

Para Hannah Arendt, o mal radical, que apareceu no totalitarismo, transcende os limites do que foi definido por Kant como o mal radical, pois trata-se de "uma nova espécie de agir humano", uma nova forma de violência "que vai além dos limites da própria solidariedade do pecado humano", de "um mal absoluto porque não pode ser atribuído a motivos humanamente compreensíveis". 0 fenômeno totalitário revelou que não existem limites às deformações da natureza humana e que a organização burocrática de massas, baseada no terror e nas ideologias, criou novas formas de governo e ideologias, cuja perversidade não se pode medir. (SOUKI, 1998, p. 33, com destaque no original)

Mas como pensar a banalidade do mal quando não estamos a lidar com regimes totalitários? 0 conceito não se aplicaria a regimes políticos formalmente democráticos e a sociedades nas quais o totalitarismo não é a regra? As indagações encerram problemas teóricos e metodológicos complexos, considerando que o conceito de banalidade do mal tem sido explorado para as mais diversas situações, em esferas de ações humanas também variadas. Acreditamos que 0 potencial heurístico do conceito de banalidade do mal extrapola as condições históricas que levam à sua proposição por Hannah Arendt e 0 inscreve no terreno das reflexões sobre uma modalidade de filosofia política original, capaz de nos permitir a compreensão de ações políticas e atitudes individuais cotidianas situadas em sociedades e regimes não totalitários. Ao mesmo tempo, a ideia de banalidade do mal nos possibilita situar 0 mal sem 0 acento maniqueísta que 0 colocaria em oposição ao bem. Como categorias filosóficas, éticas ou morais, os termos, quando colocados em oposição, servem apenas para tipos de separações como aquelas operadas pelo nazismo: 0 mal são eles, nossos inimigos, nós somos o bem, ou a sua representação. Se aceitamos tal argumento, a luta entre 0 suposto bem e 0 presumido mal justifica 0 emprego de quaisquer estratégias monstruosas. Em outros termos, a noção de banalidade do mal chama a atenção para o fato de ele poder ser praticado em quaisquer circunstâncias em 
que a ética, a tolerância e 0 respeito à alteridade são postos de lado. E essa possibilidade não se restringe a uma única forma de ação políticoideológica, de atitude individual ou coletiva, ou de modo de organização e operação do Estado.

Recorrendo mais uma vez a Nádia Souki:

0 problema do mal passa, então, a ser questionado dentro da sua dimensão política, numa visão original que é a da sua "banalidade". Com isso, ocorre uma ampliação do pensamento político de Hannah Arendt. $E$, através desse deslocamento, ela pode renovar suas esperanças no homem, resgatando o papel de agente transformador da história, ou em outras palavras, de agente político. (SOUKI, 1998, p. 35 , com destaque no original)

Pensamos que, também, o conceito de banalidade do mal nos situa diante da necessidade de antecipação, a partir das manifestações da intolerância, do ódio, dos preconceitos e demais formas de negação da alteridade, das possibilidades de sua disseminação a ponto de colocar sob risco o convívio plural e respeitoso em uma determinada sociedade. Se governos e estados têm sido o foco privilegiado das análises políticas que denunciam autoritarismos, desrespeito à vivência plural e democrática e ameaça aos direitos humanos, é preciso não circunscrever a eles e seus burocratas em todos os níveis nossa atenção. A ação política é mais abrangente que isso, como demonstram estudos de diversos matizes teóricos, mas especialmente, se queremos abraçar a esperança na espécie humana, é preciso reconhecê-la como contraditória, como capaz do belo e do ignominável, do respeito e do desprezo. $\mathrm{E}$ tais ações não dependem de políticas governamentais ou de Estado, ainda que elas possam ser fundamentais para a manutenção do convívio social na diferença e na diversidade. Por isso, a atenção deve se dar também aos pequenos movimentos vindos dos homens comuns, dos Eichmann sem nazismo a lhes dizer o que fazer, mas, ainda assim, capazes de atrocidades, em palavras, infelizmente, muitas vezes transformadas em atos. Exemplos nessa direção, como citamos, são numerosos atualmente no Brasil, em todos os espectros político-ideológicos.

Como já indicamos, a intolerância é um dos pilares de sustentação e espraiamento da banalidade do mal. Queremos voltar brevemente a Paul Ricoeur (1995), que, ao tratar da intolerância, conclui que intolerável é 0 intolerante. Trata-se, para 0 filósofo, de um problema centrado na admissão das diferenças, o que deve perpassar a discussão sobre 0 que são a tolerância e a intolerância, termos aos quais ele acrescenta a ideia do tolerável e do intolerável. Se a intolerância - ou seu oposto não mais entendido como mero tolerar, mas como a admissão plena das diferenças como constituintes da sociedade e das alteridades - é colocada como problema, o é a partir de modos de exclusão culturalmente instituídos, e, portanto, superáveis, ou na proposição de Ricoeur, do não admitir uma maneira de pensar ou de agir diferente da nossa ou daquela sancionada socialmente. Tolerância, em termos da alteridade pelo viés antropológico 
e filosófico ricoeuriano, insistimos, é aceitação plena do outro, a partir do princípio já descrito do reconhecimento desse outro em mim mesmo.

A ética, como consequência das proposições de Paul Ricoeur sobre a tolerância e a alteridade, deve ser entendida como agir bem em e para um mundo bom e justo. Trata-se de compreender a ética como parte da ação e não somente como um plano filosófico mais geral de possibilidades, do mesmo modo que não se trata de pensá-la exclusivamente em termos de regras de conduta, por exemplo, aquelas previstas em códigos deontológicos profissionais. Agir bem em um mundo bom e justo implica criar as próprias condições para que esse mundo bom e justo saia do plano utópico, do não lugar, para a existência concreta, para um lugar definido, segundo princípios da aceitação irrestrita da alteridade, 0 que constitui, certamente, um necessário circuito virtuoso marcado pelo pleno reconhecimento das pluralidades e das diferenças.

\section{Crimes contra mulheres e comentários intoleráveis}

Teorias desenvolvidas a partir da contribuição de estudos feministas têm permitido compreender os crimes contra mulheres como resultantes de dinâmicas próprias das relações de gênero (BUTLER, 2007; 2008; LOUR0, 2004; 2007; CARVALHO, 2012), as quais misturam misoginia, machismo e patriarcalismo. Ao estabelecerem falsas hierarquias fundadas em suposta superioridade masculina, as relações de gênero propiciam um ambiente favorável a que os crimes sejam não somente praticados, como ainda justificados, por exemplo, em nome da honra. Definidos em tradições teóricas que ressurgiram mais recentemente como femicídios (PASINATO, 2011), os crimes contra mulheres motivados por relações de gênero, apesar de terem se transformado em problema político grave, com a aprovação de leis, no caso brasileiro, que os tipificam e criam mecanismos de proteção, estão longe de solução do ponto de vista da consciência social da necessidade de extirpá-los, realidade que atinge provavelmente a totalidade das sociedades contemporâneas.

Tal é o cenário que nos moveu para pesquisar a cobertura jornalística, nos sites UOL (Brasil) e Público (Portugal), com os comentários sobre cada narrativa que tratava da violência - física e/ou simbólica - contra mulheres em crimes de proximidade implicados em relações de gênero. Embora a literatura majoritariamente trate dos crimes de proximidade como aqueles cometidos por parceiros, ex-parceiros ou familiares, em alguns casos estendendo para as relações de vizinhança, lidamos com a perspectiva de que nossas sociedades são por demais complexas (BECK, 1997; GIDDENS, 1991), o que exige outras modalidades de confiança (LHUMANN, 1996) socialmente construídas, ou ao menos presumidas, as quais colocam as mulheres em relações cotidianas de proximidade com colegas de trabalho, de escola, de religião e outras formas 
associativas, além de prestadores de serviços diversos, como entregas de gás ou comida em casa, operadores de transportes públicos e autoridades policiais. Ao denominarmos essas relações como de proximidade, estamos indicando que elas se fundam em um tipo de confiança, que, embora distinto daquele das relações de parentesco, por laços afetivo-sexuais ou de vizinhança, constitui modalidades de convívio diário, ainda que compulsórios, em função de necessidades de variadas ordens. Essa expansão das relações de proximidade, do ponto de vista teórico e metodológico, nos permite um quadro mais completo da dimensão da violência contra mulheres, indicando tratar-se de problema político efetivamente sério e centrado em sentimentos como posse, ódio, intolerância e, nos termos que aqui nos ocupa, demonstradores da banalidade do mal. Ademais, essa noção de proximidade surge da própria lida empírica com corpus de narrativas jornalísticas, nas quais os casos de assassinatos e outras modalidades de violências físicas, além das simbólicas, indicavam um espectro de agressores que nos levaram a questionar os limites da visão tradicional dos crimes de proximidade contra mulheres em relações de gênero.

Conforme já indicamos, não nos deteremos na complexa definição da internet, complexidade que se avoluma quando a pensamos nos marcos de novos arranjos políticos. Como qualquer produto humano, a internet está sujeita a contradições nos seus usos e não se trata de opor potencialidades democratizantes a projetos autoritários e de controle social, posto que ambos estão em um mesmo patamar de possibilidades, a depender de forças político-sociais em suas negociações. Ao tratarmos dos comentários que escancaram a intolerância e a banalidade do mal, não estamos advogando por um controle de conteúdo da internet sob a forma de censura ou de legislações capciosas que sirvam a interesses cerceadores da liberdade de expressão. Mas, certamente, trata-se de um alerta sobre a necessária responsabilização e coibição do que infringe leis de proteção aos direitos humanos e os limites das possibilidades de expressar opinião, portanto, considerando que há crimes, como propagação do ódio ou seu estímulo, difamação e assassinato de reputações, para não nos estendermos na lista, que dizem claramente que nem tudo pode ser dito ou escrito. A internet, como terra de ninguém, pode ser, contraditoriamente, um promissor lócus para o exercício da pluralidade, da democracia, da diversidade e do convívio na aceitação e pleno reconhecimento das diferenças, mas também 0 oposto, terreno onde vicejam o ódio, o preconceito, 0 desrespeito às leis e aos direitos humanos elementares. Construir coletivamente a primeira via é um desafio que se impõe.

De um total de 38 narrativas coletadas no $U O L, 29$ vieram acompanhadas de comentários de leitores, os quais perfizeram 815 intervenções, sendo que em 15 notícias os leitores manifestaram posições hegemônicas desfavoráveis às mulheres vítimas dos crimes, número que se eleva para 18 quando 
o posicionamento é desfavorável aos agressores. Em 5 matérias, os comentários são hegemonicamente favoráveis às vítimas, enquanto em 7 a mesma posição é adotada relativamente aos agressores. As demais narrativas são acompanhadas de comentários de leitores com posicionamento hegemonicamente neutro. Ainda importante como nota metodológica é o fato de algumas narrativas possuírem número elevado de comentários, a exemplo dos que acompanham a notícia de que 0 apresentador de televisão Faustão pediu desculpas no ar por grosseria praticada a vivo com sua assistente de palco, um domingo após o ocorrido e em decorrência das críticas negativas que ele recebeu ao longo da semana. Nesse caso, a agressão em si fica em plano secundário, sobressaindo-se críticas, muitas delas em tom de intolerância, contra 0 apresentador e a Rede Globo.

Chama a atenção que, além de posições favoráveis aos agressores, tenhamos detectado posicionamentos desfavoráveis às vítimas, motivando-nos a refletir acerca da banalidade do mal e do fato de ele ser demonstrado, até prova em contrário, por pessoas comuns, os Eichmann sem nazismo anteriormente referidos. Certamente, pessoas que não se envergonham de a humanidade já ter vivido tempos sombrios e de terror como aqueles tão bem capturados por Hannah Arendt. Como muitos comentários são anônimos, não é possível identificar com precisão o gênero de quem os emite, mesmo quando nicknames são masculinos ou femininos. De difícil verificação é também a veracidade da cidade ou região de moradia, pela liberdade de postar comentários sem controles rígidos. Desse modo, um mapa que "territorializasse" quem comenta seria sempre um exercício de aproximação, ainda que importante para uma percepção mais detalhada das regiões com mais pessoas comentadoras propensas à banalidade do mal.

A leitura em conjunto dos comentários chama a atenção para a defesa da pena de morte; a culpabilização das mulheres por terem sido vítimas, com "argumentos" em torno do caráter vagabundo delas, por exemplo; a indicação de que agrediria fisicamente a mulher se estivesse no lugar de personagens agressores; tentativas de desqualificar estatísticas e leis que protegem as mulheres, sob o "argumento" de que o homem estaria se transformando em vítima de artifícios inventados por elas em denúncias infundadas; além de comentários nos quais o tema central é abandonado para se tecer considerações acerca de políticos e governantes. Claro, há comentários em sentido oposto, de defesa das vítimas, mas, em muitos deles, a intolerância somente muda de lado. Na sequência, apresentamos quatro exemplos de comentários que ilustram o que entendemos como a banalidade do mal. Como se perceberá, classificá-los assim pressupõe os contornos anteriormente delineados sobre nosso entendimento das possibilidades de a filosofia política de Hannah Arendt nos auxiliar 
na detecção do espraiamento da intolerância.

Os comentários serão mantidos na forma de sua digitação tal como foram coletados.

Em artigo que mescla informação e opinião, a jornalista Johanna Nublat, sob o título Aqui ninguém mete a colher ${ }^{3}$, narra as dificuldades de aprovação de lei chinesa à semelhança da brasileira de proteção e prevenção de violências contra mulheres, que ficou conhecida como Lei Maria da Penha. Um dos comentários, postado pelo nickname Logical Think, que usa o desenho de um homem apontando a arma para a própria cabeça como identificação visual, afirma que "a Lei Maria da Penha é uma aberração, e não caberia em qualquer país sério". Além da desqualificação da lei, importante instrumento jurídico de prevenção de crimes contra mulheres e de punição aos agressores, a imagem utilizada como identidade visual parece-nos fundamental para 0 entendimento da banalização do mal pelo estímulo à violência. A propósito, as imagens que acompanham os nicknames, em conjunto, são parte da banalização do mal, seja no exemplo referido, seja na utilização de imagens que expressam ódio, por exemplo.

Da notícia sobre 0 assassinato de uma dançarina de funk (Câmeras mostram marido matando dançarina de funk na Baixada Fluminense ${ }^{4}$ ), identificamos simultaneamente em um comentário preconceito social e estético e culpabilizaçãa da vítima. Interessante é que o nickname, se pertence efetivamente a uma mulher, indica que as relações de gênero levam a que também elas manifestem sentimentos típicos de homens misóginos e machistas. "Se fosse linda por dentro não estaria nesse lixo de baile funk. Quer encontrar o que num lugar desses.. um príncipe???", indaga Ruth Giggio, identificada com desenho do personagem infantil Topo Giggio.

\section{"GERALMENTE QUANDO SE SOFRE UM} ABUSO SE FICA RETRAÍDA...ELA FICOU VULGAR." É assim que o nickname Mary Winchester, identificado com foto de rosto de uma mulher, comenta matéria relatando estupro sofrido pela cantora Madonna na juventude (Madonna fala sobre estupro que sofreu aos 19 anos $^{5}$ ). Outra vez, trata-se, possivelmente, de mulher demonstrando intolerância com uma semelhante, mas a destacar também 0 sobrenome do nickname, o mesmo de famosa marca de arma de fogo. 0 último exemplo é de comentário sobre matéria que relata agressão de mulheres a garçons, por terem sido molestadas enquanto trocavam carícias num bar, segundo texto com informações confusas, com link que remete a um vídeo (Vídeo mostra 
mulheres agredindo garçons $\left.{ }^{6}\right)$. Sob o nickname

Batman, e sem ilustração identificando, 0 comentário usa tom agressivo para atacar a Lei Maria da Penha: "Com a lei 'vadia tá prenha' essas ordinárias vão fazer o que quiser e homem nenhum poderá falar nada".

Esses exemplos ilustram como preconceito, intolerância, hierarquias de gênero, ódio e outras manifestações depreciativas são indícios claros de que a banalidade do mal é um fenômeno político, com matizes culturais e comportamentais, que tem nos comentários de internet que compõem nosso corpus uma indicação preocupante do quanto o reconhecimento da alteridade e a aceitação da diferença e da diversidade estão sob ameaça na sociedade brasileira.

\section{Conclusão}

Essa breve análise dos comentários, a qual poderia ser acrescida de outras variáveis ou aprofundada naquelas que abordamos se tivéssemos tempo e espaço mais expandidos, indica ser necessário pensar a comunicação em termos de disputas de sentido, de jogos de poder, e não como uma seara romanticamente vista como 0 reino das interações, como o primado do relacional que desconhece as hierarquias. Em suma, tornar mais politizadas as visadas sobre a comunicação, suas processualidades e produtos, sem os ranços dos determinismos e das influências unilaterais, que marcaram e ainda marcam algumas premissas teórico-metodológicas, mas, certamente, sem a ingenuidade epistemológica que se compromete com ações políticas reafirmadoras das intolerâncias, do mal e dos preconceitos, às vezes pela simples negligência de temáticas socialmente controversas ou pela incapacidade de perceber as contradições no interior do que está sob escrutínio. É imperativo reconhecer que lidamos com um campo de conhecimento essencialmente marcado pelos entrelaçamentos com o social, suas clivagens e contradições, presentes em quaisquer temáticas sob investigação.

Voltando ao início das nossas reflexões, a militância intelectual se faz necessária em tempos sombrios. Por essa razão, é importante pensar nas especificidades dos próprios desafios teóricos e metodológicos da comunicação como chave para uma militância intelectual nos marcos das nossas especificidades, reivindicando compromissos epistemológicos que situem investigações e teorizações por meio de compromissos com a superação das intolerâncias, dos ódios, das violências físicas e simbólicas, o que requer postura crítica relativamente, talvez, à maioria dos nossos atuais modos de pensar a comunicação, suas processualidades e seus produtos. A internet, até em função das suas potencialidades e contradições já referidas, oferece um vasto campo de possibilidades analíticas nessa direção. 
Por seu turno, as reflexões sobre a banalidade do mal e a intolerância que acionamos, a partir de Hannah Arendt e de Paul Ricoeur, se inscrevem na necessidade de não pensarmos a comunicação apartada de questões socioculturais, mas também apontam para o fato de que nossa área de investigação continua tributária de outras esferas do conhecimento. Antes de constituir uma deficiência, essa recorrência é indicativa do atravessamento político-cultural, que é da natureza das mútuas afetações entre a comunicação, seus produtos e processualidades e as dinâmicas e atores sociais com os quais disputa sentidos e se envolve em jogos de poder.

Ao reivindicarmos a potencialidade heurística do conceito de banalidade do mal para a explicitação do comportamento das pessoas que comentaram narrativas jornalísticas sobre crimes de proximidade contra mulheres em relações de gênero, tivemos em mente que a proposição original de Hannah Arendt, identificada com reflexões centradas na esfera da filosofia política, mantém-se não somente atual, como capaz de jogar luzes sobre diversas ações humanas. No que acreditamos ser a manutenção do tom de denúncia que acompanha as reflexões da filósofa, reafirmamos que é urgente perceber em atitudes de intolerância como as aqui relatadas, e não somente nos comentários de leitores, os indícios de uma sociedade que caminha para a adoção de práticas de ódio e intolerância, as quais precisam ser detidas antes de inviabilizarem a construção de uma sociedade centrada na pluralidade, no respeito às diferenças e à alteridade.
Nessa perspectiva, instrumentos teóricometodológicos da comunicação têm contribuições a oferecer a outras áreas de investigação, dentre outras razões, porque lidam com as efervescências sociais no momento mesmo em que elas estão surgindo. Olhares atentos e críticos sobre produtos e processualidades midiáticas - com especial atenção para as opiniões das "pessoas ordinárias" por meio dos espaços de comentários -, potencialmente, nos permitirão agir preventivamente para evitar a instauração do mal, segundo a lógica da banalidade, dos seus modos de manifestação e do seu espraiamento.

\section{Referências}

ARENDT, Hannah. Origens do totalitarismo: antisemitismo, imperialismo, totalitarismo. São Paulo: Companhia das Letras, 1989.

\section{Eichmann em Jerusalém:}

uma reportagem sobre a banalidade do mal. Coimbra: Edições Tenacitas, 2003.

BECK, Ulrich. A reinvenção da política: rumo a uma teoria da modernização reflexiva. In: BECK, Ulrich, GIDDENS, Anthony, LASCH, Scott. Modernização reflexiva: política, tradição e estética na ordem social moderna. São Paulo: Editora da Universidade Estadual Paulista, 1997.

BREDIN, Jean-Dennis. 0 caso Dreyfus. São Paulo: Scritta, 1995.

BUTLER, Judith. Corpos que pesam: sobre os limites discursivos do "sexo". In: LOUR0, Guacira Lopes (org.). 0 corpo educado: pedagogias da sexualidade. Belo Horizonte: Autêntica, 2007.

BUTLER, Judith. Problemas de gênero: feminismo e subversão da identidade. Rio de Janeiro: Civilização Brasileira, 2008. 
CARVALHO, Carlos Alberto de. Jornalismo, homofobia e relações de gênero. Curitiba: Editora Appris, 2012.

ERIBON, Didier. Reflexões sobre a questão gay. Rio de Janeiro: Companhia de Freud, 2008.

GIDDENS, Anthony. As consequências da modernidade. São Paulo: Editora da Universidade Estadual Paulista, 1991.

LOUR0, Guacira Lopes (org.). 0 corpo educado: pedagogias da sexualidade. Belo Horizonte: Autêntica, 2007.

LOURO, Guacira Lopes. Um corpo estranho: ensaios sobre sexualidade e teoria queer. Belo Horizonte: Autêntica, 2004.

LUHMANN, Niklas. Confianza. Barcelona, Anthropos, 1996.

MARQUES, António. A filosofia e o mal: banalidade e radicalidade do mal de Hannah Arendt a Kant. Lisboa: Relógio d'Água, 2015.

NAPHY, Willian. Born to be gay. História da homossexualidade. Lisboa: Edições 70, 2004.

PASINATO, Wânia. "Femicídios" e as mortes de mulheres no Brasil. Cad. Pagu, Campinas, $\mathrm{n}^{0}$ 37, dez. 2011. Disponível em http://www.scielo. br/scielo.php?script $=$ sci_arttext\&pid $=$ S0104$83332011000200008 \& \operatorname{lng}=$ pt\&nrm $=$ iso.

RICOEUR, Paul. 0 si-mesmo como um outro.

Campinas: Papirus, 1991. . Tempo e narrativa - Tomo I.

Campinas: Papirus, 1994.

Leituras 1: em torno ao político.

São Paulo: Loyola, 1995.

SCHWAB, Jean-Luc \& BRAZDA, Rudolf. Triângulo rosa: um homossexual no campo de concentração nazista. São Paulo: Mescla, 2011.
SOUKI, Nádia. Hannah Arendt e a banalidade do mal. Belo Horizonte: Editora UFMG, 1998.

SPENCER, Colin. Homossexualidade: uma história. Rio de Janeiro: Record, 1996. 


\section{Banality of evil in reader comments: internet and dissemination of intolerance}

\section{Abstract}

From reader comments about journalistic narratives about events involving closeness' crimes against women in gender relations this article, of essayistic nature, seeks on the concept of banality of evil to understand intolerance dynamics. At the same time that we assumed clear militancy against forms of prejudice, hate and other arrangements for the human depreciation, we alert to the need to think about theoretical assumptions that can conduct research in the communication area not to pay attention to the social contradictions, games' power and the refusal to accept the difference as a constitutive principle of human and social richness.

\section{Keywords}

Banality of evil. Reader comments. Intolerance.

\section{Banalidad del mal en comentarios de los lectores: Internet y la propagación de la intolerancia}

\section{Resumen}

Desde comentarios de lectores sobre noticias acerca de acontecimientos relacionados con crímines de proximidad contra las mujeres en relaciones de género, el artículo, de naturaleza ensayística, busca en el concepto de banalidad del mal entender la dinámica de la intolerancia. Al mismo tiempo em que asumimos la militancia clara contra las formas de prejuicio, el odio y otras formas de depreciación humana, advertimos sobre la necesidad de pensar los propios supuestos teóricos que pueden conducir investigaciones en el área de comunicación a no prestar atención a las contradicciones sociales, a los juegos del poder y la denegación a aceptar la diferencia como principio constitutivo de la riqueza humana y social.

\section{Palabras clave}

Banalidad del mal. Comentarios de los lectores. Intolerancia. 


\section{Expediente}

A revista E-Compós é a publicação científica em formato eletrônico da Associação Nacional dos Programas de Pós-Graduação em Comunicação (Compós). Lançada em 2004, tem como principal finalidade difundir a produção acadêmica de pesquisadores da área de Comunicação, inseridos em instituições do Brasil e do exterior.

\section{E-COMPÓS I www.e-compos.org.br I E-ISSN 1808-2599}

Revista da Associação Nacional dos Programas de Pós-Graduação em Comunicação. Brasília, v.19, n.2, maio/ago. 2016. A identificação das edições, a partir de 2008, passa a ser volume anual com três números. Indexada por Latindex I www.latindex.unam.mx

\section{CONSELHO EDITORIAL}

\section{Alexandre Farbiarz, Universidade Federal Fluminense, Brasi}

Alexandre Rocha da Silva, Universidade Federal do Rio Grande do Sul, Brasil Ana Carolina Escosteguy, Pontifícia Universidade Católica do Rio Grande do Sul, Brasil Ana Carolina Rocha Pessôa Temer, Universidade Federal de Goiás, Brasil Ana Regina Barros Rego Leal, Universidade Federal do Piauí, Brasil Andrea França, Pontifícia Universidade Católica do Rio de Janeiro, Brasil André Luiz Martins Lemos, Universidade Federal da Bahia, Brasil Antonio Carlos Hohlfeldt, Pontifícia Universidade Católica do Rio Grande do Sul, Brasil Arthur Ituassu, Pontifícia Universidade Católica do Rio de Janeiro, Brasil Álvaro Larangeira, Universidade Tuiuti do Paraná, Brasil

Ângela Freire Prysthon, Universidade Federal de Pernambuco, Brasil César Geraldo Guimarães, Universidade Federal de Minas Gerais, Brasil Cláudio Novaes Pinto Coelho, Faculdade Cásper Líbero, Brasil Daisi Irmgard Vogel, Universidade Federal de Santa Catarina, Brasil Denize Correa Araujo, Universidade Tuiuti do Paraná, Brasil Eduardo Antonio de Jesus, Pontifícia Universidade Católica de Minas Gerais, Brasil Daniela Zanetti, Universidade Federal do Espírito Santo, Brasil Eduardo Vicente, Universidade de São Paulo, Brasil

Elizabeth Moraes Gonçalves, Universidade Metodista de São Paulo, Brasil Erick Felinto de Oliveira, Universidade do Estado do Rio de Janeiro, Brasil Francisco Elinaldo Teixeira, Universidade Estadual de Campinas, Brasil Francisco Paulo Jamil Almeida Marques, Universidade Federal do Paraná, Brasil Gabriela Reinaldo, Universidade Federal do Ceará, Brasil

Goiamérico Felício Carneiro Santos, Universidade Federal de Goiás, Brasil Gustavo Daudt Fischer, Universidade do Vale do Rio dos Sinos, Brasil Herom Vargas, Universidade Municipal de São Caetano do Sul, Brasil Itania Maria Mota Gomes, Universidade Federal da Bahia, Brasil Janice Caiafa, Universidade Federal do Rio de Janeiro, Brasil Jiani Adriana Bonin, Universidade do Vale do Rio dos Sinos, Brasil
José Afonso da Silva Junior, Universidade Federal de Pernambuco, Brasil José Luiz Aidar Prado, Pontifícia Universidade Católica de São Paulo, Brasil Juçara Gorski Brittes, Universidade Federal de Ouro Preto, Brasil Kati Caetano, Universidade Tuiuti do Paraná, Brasil Lilian Cristina Monteiro França, Universidade Federal de Sergipe, Brasil Liziane Soares Guazina, Universidade de Brasilia, Brasil Luíza Mônica Assis da Silva, Universidade de Caxias do Sul, Brasil Luciana Miranda Costa, Universidade Federal do Pará, Brasil Malena Segura Contrera, Universidade Paulista, Brasil Monica Martinez, Universidade de Sorocaba, Brasil Maria Ataide Malcher, Universidade Federal do Pará, Brasil Marcia Tondato, Escola Superior de Propaganda e Marketing, Brasil Marcel Vieira Barreto Silva, Universidade Federal da Paraiba, Brasil Maria Clotilde Perez Rodrigues, Universidade de São Paulo, Brasil Maria das Graças Pinto Coelho, Universidade Federal do Rio Grande do Norte, Brasil Mauricio Ribeiro da Silva, Universidade Paulista, Brasil

Mauro de Souza Ventura, Universidade Estadual Paulista, Brasil Márcio Souza Gonçalves, Universidade do Estado do Rio de Janeiro, Brasil Micael Maiolino Herschmann, Universidade Federal do Rio de Janeiro, Brasil Mirna Feitoza Pereira, Universidade Federal do Amazonas, Brasil Nísia Martins Rosario, Universidade Federal do Rio Grande do Sul, Brasil Potiguara Mendes Silveira Jr, Universidade Federal de Juiz de Fora, Brasil Regiane Regina Ribeiro, Universidade Federal do Paraná, Brasil Rogério Ferraraz, Universidade Anhembi Morumbi, Brasil Rose Melo Rocha, Escola Superior de Propaganda e Marketing, Brasil Rozinaldo Antonio Miani, Universidade Estadual de Londrina, Brasil Sérgio Luiz Gadini, Universidade Estadual de Ponta Grossa, Brasil Simone Maria Andrade Pereira de Sá, Universidade Federal Fluminense, Brasil Veneza Mayora Ronsini, Universidade Federal de Santa Maria, Brasil Walmir Albuquerque Barbosa, Universidade Federal do Amazonas, Brasil
COMISSÃO EDITORIAL Eduardo Antonio de Jesus, Pontifícia Universidade Católica de Minas Gerais, Brasil I Osmar Gonçalves dos Reis Filho, Universidade Federal do Ceará, Brasi

CONSULTORES AD HOC Alexandre Almeida Barbalho, Universidade Estadual do Ceará, Brasil | Alexandre Rocha da Silva, Universidade Federal do Rio Grande do Sul, Brasil | Bruno Souza Leal, Universidade Federal de Minas Gerais, Brasil I Carlos Eduardo Franciscato, Universidade Federal do Sergipe, Brasil I Eneus T. Barreto Filho, Universidade de São Paulo, Brasil I Felipe da Costa Trotta, Universidade Federal Fluminense, Brasi | Henrique Codato, Universidade Federal do Ceará, Brasil I Ines S. Vitorino Sampaio Universidade Federal do Ceará, Brasil I Jairo Getulio Ferreira, Universidade do Vale do Rio dos Sinos, Brasil I Juliana Freire Gutmann, Universidade Federal da Bahia, Brasil | Júlio César M. Pinto, Pontifícia Universidade Católica de Minas Gerais, Brasil I Lucrecia D. Ferrara, Pontifícia Universidade Católica de São Paulo, Brasil I Marcio V. Serelle, Pontifícia Universidade Católica de Minas Gerais, Brasil I Maria Ignes C. Magno, Universidade Anhemb Morumbi, Brasil I Maria Lilia Dias de Castro, Universidade Federal de Santa Maria, Brasil | Mozahir S. Bruck, Pontifícia Universidade Católica de Minas Gerais, Brasil I Potiguara M. da Silveira Junior, Universidade Federal de Juiz de Fora, Brasil I Sandra Maria L. P. Gonçalves, Universidade Federal do Rio Grande do Sul, Brasil I Suzana Kilpp, Universidade do Vale do Rio dos Sinos, Brasil I Tiago Q. Fausto Neto, Universidade de Brasília, Brasil I Vera Regina V. Franca, Universidade Federal de Minas Gerais, Brasil I Virginia P. S. Fonseca, Universidade Federal do Rio Grande do Sul, Brasil

EQUIPE TÉCNICA ASSISTENTE EDITORIAL Márcio Zanetti Negrini REVISÃo DE TEXTOS Press Revisão I EDITORAÇÃO ELETRÔNICA Roka Estúdio

\section{COMPÓS I www.compos.org.br}

Associação Nacional dos Programas de Pós-Graduação em Comunicação

Presidente

Edson Fernando Dalmonte

Programa de Pós-Graduação em Comunicação

e Cultura Contemporânea - UFBA

edsondalmonte@uol.com.br

Vice-presidente

Cristiane Freitas Gutfreind

Programa de Pós-Graduação em Comunicação Social - PUC-RS cristianefreitas@pucrs.br

Secretário-Geral

Rogério Ferraraz

Programa de Pós-Graduação em Comunicação

Universidade Anhembi Morumbi

rogerioferraraz@anhembimorumbi.edu.br

CONTATO I revistaecompos@gmail.com 